year, $£ 12 \mathrm{~m}$. has been voted for the capital expenditure of hospitals in Great Britain, and, according to the statements made last week, much the same sums will be available in 1956-7 and 1957-8. What the main part of the new programme will do is to inaugurate the building of entirely new hospitals 'for the first time since before the war. Parliament will be asked to vote a sum of $£ 7 \frac{1}{2} \mathrm{~m}$. for England and Wales in 1956-7 and $£ 10 \mathrm{~m}$. in $1957-8$ to enable major building projects to be undertaken.

Compared with expenditure in the decade before the war, when a vast amount of hospital building was carried out from voluntary funds and by public authorities, these sums, as Mr. Macleod pointed out, are not large. On the other hand, much of the building by the voluntary system in the 'thirties took the shape of small hospitals, scattered haphazardly over the country according to the wishes of the benefactors, local enterprise, and local wealth. In the public system, similarly, energetic local authorities were busy putting up new hospitals or converting their old public assistance institutions. But here, too, though such relatively well-off public authorities as London and Middlesex carried out some big hospital schemes, some of the poorer authorities were impeded by lack of funds. Now that all hospital expenditure is met from central funds, there should be a much better chance of the new building taking place where it is most needed and of the money available being put to better use. Certainly the list of projects given by Mr. Macleod that witl be included in the first year's programme looks as if absence or shortage of existing accommodation in relation to population has been the main criterion in deciding priority. Thus a new town like Harlow' and a greatly to be expanded old town like Swindon are to have new general hospitals. West Cornwall and West Cumberland, at present without adequate general hospitals, are to have them. The present shortage of mental hospital accommodation in the Midlands is reflected in the new mental hospital to be built at Wolverhampton, and four regions are to have major extensions to their mental deficiency hospitals. The rebuilding of Charing Cross Hospital at Harrow, possibly to start in 1957-8, had been decided on long ago; it is an obvious advantage to disperse some of the teaching hospital facilities of Central London to areas of growing population outside.

In other cases, however, the reason for priority seems less clear, at least to those not privileged to know what guides a regional board in coming to a decision. Four hospitals were mentioned by Mr. Macleod as being allowed to start building new outpatient departments in 1956-7. Their need for them is not disputed. But what the staffs of other hospitals whose need is apparently no less.great would like to know is why their hospitals' claims have again been postponed. Publication of the reasons for postponement might help to allay the customary suspicion that priority is given to those who make most fuss.

The second smaller part of the new programme is a special allocation of money to be used for plant replacement and "redeployment," whatever that may prove to be. For this purpose Parliament will be asked to vote $£ 2 \mathrm{~m}$ in $1956-7$ and $£ 4 \mathrm{~m}$. in $1957-8$. The replacement of antiquated plant in boiler rooms and laundries has long been recognized as a means of economizing in maintenance expenditure, and the new financial provision is intended to give a fillip to schemes of this sort, which can already-subject to Ministerial approval-be carried out under the Boards' ordinary capital programmes.

Nevertheless, such economies as are obtained in this way must be small in relation to the hospitals' total maintenance expenditure. This is bound to be increased when the new hospitals are ready to be staffed and used. Here, too, a point arises. Will the additional staff be forthcoming? Mr. Macleod seemed to have no qualms about this on being questioned, because, he said, hospital staffs had been steadily increasing since 1948 , and it would be easier to attract staff to new hospitals. Nevertheless, there is a danger, particularly in the mental hospitals and mental deficiency institutions, which are already short of nurses, that the new hospitals will not recruit additional staff but merely attract staff away from the old.

The new schemes are only a foretaste of what needs to be done. But at least a beginning is to be made, and at last hospital boards have been given a longterm period for planning - and, moreover, a definite undertaking that, subject to Parliament's approval, the necessary funds will be forthcoming.

\section{RESULTS OF TREATING CANCER OF THE LUNG}

Carcinoma of the bronchus is a disease with a bad prognosis : often no treatment is possible, and in other cases only temporary palliation can be hoped for. But when radical surgery is possible a substantial hope of a long survival can be offered; and in the majority of cases life is prolonged. The benefits of surgery, disappointing though it often is, are greater than is generally believed. Elsewhere in this issue Mr. T. Holmes Sellors reviews the results of surgery in the cases he has himself treated. Between 1940 and 1950 he undertook 689 thoracotomies, and found excision possible in 446 . Of 273 resections performed between 1940 and 1948, 24\% of the patients died within four months of operation, but $34 \%$ survived 
two years, and $21 \%$ five years. Of 173 resections performed in 1949 and $1950,9 \%$ of the patients died within four months of operation, and $40 \%$ survived two years, and $34 \%$ three years. Results of surgery are thus better than they used to be and are still improving. In 1946 Tudor Edwards ${ }^{1}$ published his personal results in the first number of Thorax: of 1,016 patients seen with bronchial carcinoma, 173 were operated on and excision carried out on 70 . Operative mortality was $17 \% ; 27 \%$ of the patients survived two years, and $7 \%$ five years. Another recent series, published in 1954 by Boyd and his colleagues ${ }^{2}$ from Boston, Mass., gave results comparable to those of Holmes Sellors: resection was done in 104 cases out of 403 seen, with $8 \%$ operative mortality and $32 \%$ surviving for five years. Gibbon ${ }^{3}$ reported a five-year survival rate of $26 \%$; and Ochsner ${ }^{4}$ found resection possible in 442 cases out of 1,365 , with an operative mortality of $19 \%$ and a fiveyear survival rate of $34 \%$. In considering survival rates, it must be remembered that most of these patients are in late middle or old age and that the onset of other diseases would in any event be tending to raise the mortality rate in such a group. Nevertheless many of those surviving for five years eventually die from recurrence or metastases of the original growth.

Taylor and Waterhouse, ${ }^{5}$ reporting on 1,592 cases of carcinoma of lung, found an average survival of only four months from the time of diagnosis in patients not treated by resection. Boyd and his colleagues $^{2}$ also reported that patients treated only medically survived four months ; and Lea ${ }^{6}$ found the average duration of life to be six and a half months from the first symptom. The range of variation in the time of survival of untreated patients is wide, and occasionally, as with all cancers, patients survive several years. A case of spontaneous regression has even been reported, ${ }^{7}$ but the natural course of the disease is almost always extremely short. Cure is always hoped for, though it cannot be confidently predicted even after several years' survival, but the patient who has had a resection has more than a $50 \%$ chance of surviving for a year, and so of trebling his life expectation.

Radiotherapy, which is mainly used as a palliative, also prolongs life. As Smithers ${ }^{8}$ has pointed out, the patients who would most benefit from radical radiotherapy are also suitable for surgery and so usually treated by resection. Brooks and his colleagues ${ }^{9}$ found that 129 patients given a radical course of radio-

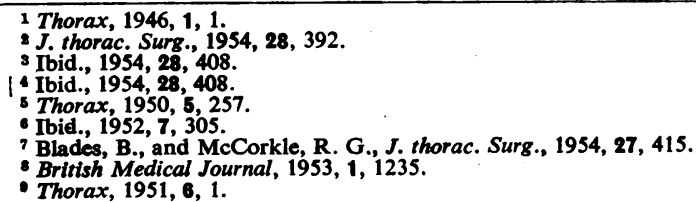

therapy survived for an average period of 10 months, and that 176 given palliative therapy lived, on average, for five and a half months. The temporary palliation of symptoms achieved by the lesser course, which, unlike radical therapy, can usually be given without causing radiation sickness, is most valuable, particularly for the relief of haemoptysis, superior vena caval obstruction, or the pain of secondary bone deposits (but not of direct bone invasion).

The advice of a surgeon should be sought whenever extension of the growth beyond the thorax has not been proved. Operation will occasionally be contraindicated by the patient's general condition (especially if respiratory function is reduced by previous disease), but more often by invasion of glands or mediastinal structures - the heart or superior vena cava, the recurrent laryngeal or phrenic nerves, or the proximal great vessels. Holmes Sellors confirms the general belief that the histological type of the carcinoma influences the operability and prognosis, squamous-celled growths being more readily and more successfully treated than adenocarcinoma or oat-celled carcinoma. The same tumour, however, may contain areas of different cellular types. Unfortunately operability cannot always be determined before exploration, and a large number of useless thoracotomies must inevitably be done if as many patients as possible are to be given the benefit of a resection. A radical operation nearly always entails a pneumonectomy, since it is usually essential to remove the main bronchus. Sometimes in peripheral growths without glandular involvement a lobectomy is enough, and in other patients with poor respiratory function it must be accepted as a palliative.

\section{ARTIFICIAL RESPIRATION AND CARBON DIOXIDE}

When a healthy man breathes air or oxygen mixed with $5 \%$ of carbon dioxide his breathing markedly deepens and quickens. This incontrovertible observation led to the emergency use of carbon dioxide in attempts to stimulate breathing when it had stopped. Haggard and Henderson $^{1}$ in 1921 advocated, for many respiratory emergencies, the use of $5 \%$ carbon dioxide with oxygen in conjunction with artificial respiration. Since then cylinders containing this mixture of gases have been widely used. There are few forms of treatment about which it is harder to obtain direct clinical evidence, for in these emergencies those present must strive urgently for the patient's life and critical observation is almost impossible. Yet it has been suspected for some time that to give carbon dioxide to a patient who needs and is receiving artificial respiration is not only irrational but may be harmful.

\footnotetext{
$1 \mathrm{~J}$. Amer. med. Ass., 1921, 77, 1065.

Donald, K. W., Lancet, 1953, 1, 495.

Scurr, C. F., British Medical Journal, 1954, 1, 565.

- Ibid., 1955, 1, 313.
} 